Mundo Agrario vol. 18, n 37, e046, abril 2017. ISSN 1515-5994

Universidad Nacional de La Plata.

Facultad de Humanidades y Ciencias de la Educación.

Centro de Historia Argentina y Americana

\title{
Política, modos de vida y sociabilidad en una pequeña sociedad rural
}

\author{
Politic, way of life and sociability in a small rural society
}

\section{Carlos Cowan Ros *}

* Centro de Estudios Urbanos y Regionales del Consejo Nacional de Investigaciones Científicas y Técnicas, Argentina | cowanros@agro.uba.ar

\section{PALABRAS CLAVE RESUMEN}

En el artículo se analiza la configuración y dinámica que adquiere la política en la Comisión Municipal de Yavi, Política interpretada como una pequeña sociedad rural. A partir de identificar los significados y las prácticas que los pobladores asocian y oponen a la política, y de observar las interacciones con procesos que ocurren a escala provincial y nacional, se propone un modelo de funcionamiento de la política yaveña. Entre los resultados se

Pequeñas sociedades observa que las prácticas políticas son animadas por múltiples motivaciones que desbordan lo considerado

Relaciones múltiples estrictamente como político y se imbrican con otras esferas de la vida social. La metodología articula el enfoque etnográfico con el estudio de caso. Los registros empíricos fueron colectados entre 1997 y 2014.

Estrategias de reproducción social

Comunidades indígenas

\section{KEYWORDS}

Politic

Small societies

Multiplex relations

Social reproduction strategies

Indigenous community

\section{ABSTRACT}

The article describes the configuration and dynamics that takes politics in the Comisión Municipal de Yavi, interpreted as a small rural society. From identifying the meanings and practices that people associate and oppose to politic and observe interactions with processes occurring at the provincial and national level, it's proposed a functioning model of politic in Yavi. The results shows that the political practices are encouraged by multiple motivations that go beyond what is considered strictly as political and overlap with other spheres of social life. The methodology articulates the ethnographic approach and the case study. The empirical observations were collected between 1997 and 2014. 


\section{Introducción}

La crisis que transitó la sociedad argentina durante el cambio de milenio, signada por el recrudecimiento de la protesta social, recolocó en parte de la academia, en especial entre cientistas sociales abocados a cuestiones urbanas, el interés por comprender las prácticas políticas de los sujetos subalternos. Entre quienes estudian la cuestión rural las características que adquiere la política en los espacios locales ha sido menos atendida. Si bien existen estudios sobre conflictos rurales y organizaciones agrarias, entiendo que la especificidad que adquiere la política en las localidades rurales fue excepcionalmente abordada como objeto de estudio. En el mismo sentido, la política en cuanto práctica que afecta al orden social, rara vez ha sido articulada en la comprensión de las estrategias de reproducción social campesinas. El análisis de éstas suele acotarse a las prácticas económicas, y rara vez se explora su relación con las lógicas de articulación con las instituciones públicas, en particular cómo éstas se vinculan y complementan con dichas prácticas definiendo modos de producción, de vida y condiciones de ascenso social.

En el presente artículo abordo esas cuestiones. Me centro en comprender cómo se configura y qué dinámica adquiere la política en la jurisdicción de la Comisión Municipal de Yavi. Realizo el abordaje a partir de identificar cómo la política es comprendida y experimentada por los yaveños, cómo a partir de los significados y prácticas que le asocian y oponen (re)configuran modos de vida e instituciones sociales específicas, y cómo la política local interactúa con procesos más amplios que ocurren a escala provincial y nacional.

Como cuestión académica la política está atravesada por diferentes tradiciones y enfoques analíticos, no siempre convergentes. Una de las tensiones se despliega sobre la entidad y supuestos que se les otorgan a la política en cuanto fenómeno empírico. A partir de la década de 1990, algunos autores (Palmeira, 1992; Abélès, 1997; Balbi y Rosato, 2003, entre otros/as) comenzaron a cuestionar la cosificación de la política en las ciencias sociales. Objetan el sesgo de concebirla como un dominio social caracterizado por acciones orientadas exclusivamente al Estado y por instituciones, profesionales y lógicas de comportamiento específicas. Entienden que la cosificación conlleva asumir que esas características diferencian a la política del resto de la sociedad, configurándose en un dominio o campo social autónomo. Atribuir a priori a lo político características universales y específicas, implica reificar lo que es dinámico, difuso y particular de cada sociedad.

Otro debate se ha expresado en los principios del comportamiento político. La idea de un proceder individual, impersonal, racional y consciente, regido por alineamientos ideológicos y/o de clase está ampliamente difundida en la literatura académica, aunque rara vez se verifique en la práctica (Alavi, 1973 y Palmeira, 1992). Abordar la política a partir de conceptos sujetos a preceptos normativos condiciona a analizarla con las categorías de pensamiento que se producen en su seno y, en consecuencia, más que a comprender su funcionamiento, lleva a reproducir una forma de pensamiento preestablecida.

Como alternativa analítica, los autores citados proponen el camino inverso. En vez de partir de la institucionalidad y de las lógicas que se espera animen el comportamiento político como cosas dadas, sugieren comprender la política como proceso que se configura en torno a representaciones, prácticas e interacciones sociales que se inscriben en relaciones de poder entre sujetos y que se expresan en diferentes escalas espaciales. Este camino analítico es propicio para reconstruir y evidenciar cómo se configura la política interdependientemente con otros ámbitos sociales. Entiendo que este enfoque adquiere particular sentido para localidades rurales que pueden ser interpretadas como sociedades a pequeña escala, conforme Burton Benedict define a los ámbitos sociales en donde existe menos posibilidad de relaciones impersonales, dado que los individuos interactúan repetidamente con las mismas personas en casi todas las situaciones sociales (1980, p. 41). En esos ámbitos lo distintivo es el trato personalizado, tanto de lo privado como de lo público. 
La persistencia de las relaciones personalizadas en las instituciones modernas genera un dilema interpretativo en las ciencias sociales, también experimentado por los agentes de promoción social. Existe cierta expectativa de que conforme se consoliden las instituciones de la Modernidad se cristalizará en ellas una lógica burocrática, en cuanto racional e impersonal, desplazando los elementos folks $\underline{1}$, entre los que destacan las relaciones clientelares o de patronazgo, consideradas resabios de la tradición. Sin embargo, las relaciones personalizadas evidencian (re)producirse y perpetuarse, incluso en contexto de Modernidad $\stackrel{2}{2}$. Sobre este dilema ensayaré aportes con vistas a comprender las condiciones de (re)producción de ese tipo de relaciones, a partir de desentrañar cómo funciona la política en Yavi.

El presente artículo es un desprendimiento de estudios realizados entre 1997 y 2014 en la provincia de Jujuy y en la jurisdicción de Yavi en los que analicé prácticas de intervención en desarrollo rural, organizativas, políticas y de rearticulación étnica, referenciadas a lo largo del texto. Las investigaciones articularon el enfoque etnográfico con la estrategia de estudio de caso, siendo éste el diseño metodológico del caso aquí analizado y el periodo de estudio coincidente con el registro de datos.

\section{Yavi: estructura organizativa, modos de vida y rearticulación étnica}

El territorio de la Comisión Municipal de Yavi se sitúa en la región andina de Puna, norte de la provincia de Jujuy, extremo norte de Argentina. Posee aproximadamente 1.300 habitantes, 200 de los cuales residirían en la localidad de Yavi y el resto en las 10 aldeas o "comunidades" que la rodean. El Instituto Nacional de Estadísticas y Censos clasifica al territorio como "rural”, porque su población es inferior a los 2.000 habitantes (INDEC, 2012).

Si se analizan las características económicas, históricas, sociales, étnicas y políticas de sus habitantes, se apreciará su doble condición subalterna, pues ocupan una posición marginada en una provincia periférica.

En la literatura científica se caracterizó a los yaveños como "campesinos semi-proletarios de origen indígena” por su ascendencia étnica y porque han complementado los ingresos provenientes de la producción agropecuaria, destinada fundamentalmente al autoconsumo, con los de la venta de mano de obra, durante la mayor parte del Siglo XX (Abduca, 1993).

En las últimas décadas del siglo pasado, las estrategias de reproducción social de los yaveños se desarticularon y entraron en crisis, debido a la retracción de la demanda de mano de obra en los destinos tradicionales de migración y empleo. Al peligrar su subsistencia las familias redefinieron sus lógicas de captación de ingresos según las escasas oportunidades del contexto. Miembros de instituciones públicas y privadas comenzaron a ejecutar proyectos de promoción social para paliar la precarización de las condiciones de vida de los habitantes. En Yavi destaca la labor de MINK'A ${ }^{3}$, una ONG laica de desarrollo rural gestionada por profesionales originarios de otras regiones del país que, desde mediados de 1990, patrocinan proyectos asociativos de producción y comercialización agropecuaria. Los programas sociales ejecutados a través de la Comisión Municipal, junto a los empleos que ésta generaba, completaban las alternativas de generación de ingresos de los yaveños (Cowan Ros y Schneider, 2008).

En 2005 aproximadamente 85\% de los grupos domésticos de Yavi accedía a recursos económicos distribuidos a través de la Comisión Municipal. A partir de 2010, con el inicio del Programa Asignación Universal por Hijo para Protección Social, la inmensa mayoría de las familias yaveñas integraron fondos públicos a su economía doméstica (Cowan Ros, 2014). La recurrente presencia de recursos provenientes del complejo político-institucional en la economía de las familias yaveñas, evidencia la relación entre sus estrategias económicas y su vinculación con la institucionalidad pública y privada de promoción social, lo que interpreto como una expresión de sus prácticas políticas. 
Es difícil postular una tipología de estrategias económicas de las familias yaveñas, dada la multiplicidad de combinaciones de actividades y la alta variabilidad según las oportunidades. Si bien existen familias más volcadas a lo agropecuario, hay una clara predisposición a la venta de mano de obra o a establecer emprendimientos de servicios (kioscos, remises u hostales), dada la mayor cuantía y certeza de los ingresos. Los rasgos más recurrentes de esas estrategias son la pluriactividad, la creciente participación de recursos de la institucionalidad de promoción social en la economía familiar y la movilidad espacial, temporaria o permanente, de todo o parte del grupo doméstico (Cowan Ros, 2013a).

Una forma de aprehender y comprender la estructura social de cualquier grupo humano es a través de las modalidades de vinculación y organización significativas para sus miembros. La red de parentesco es un grupo de referencia y vinculación relevante para los yaveños. La “comunidad” -red vecinal con intrincadas relaciones de parentesco- es la otra unidad de agregación de creciente relevancia. La Constitución Nacional de 1994 reconoció a la comunidad indígena como una institución de los pueblos originarios, le otorgó estatus jurídico y concedió a sus miembros el derecho a la titularidad colectiva de los territorios que habitan. Esta reforma institucional reactivó la cuestión indígena en la Puna y con ella la entidad comunidad. A los fines de este artículo, interesa delinear los principios de vinculación que los yaveños agencian a la “comunidad”, pues suelen oponerla a lo político en su construcción de la realidad social. $\underline{4}$

En la interpretación de la sociabilidad en las comunidades yaveñas recupero la noción comunidad moral, propuesta por Pitt Rivers (1971), pues entre sus miembros existe el sentimiento de pertenencia a un mismo grupo, predominan los vínculos cara a cara y las relaciones sociales están reguladas por un conjunto de normas y principios éticos de comportamiento. Con relación a estos últimos, los vecinos suelen invocar que el comportamiento individual debiera regirse por los valores de laboriosidad, honradez y solidaridad, que definen al "buen vecino"; en cuanto a la unión, la igualdad y la autonomía debieran guiar el comportamiento como "comunidad". En los últimos años, la objetivación y puesta en valor de esos principios de comportamiento, a manera de discurso normativo, fue favorecida por el proceso de obtención de las personerías jurídicas de comunidad indígena. En la gestión de éstas asistieron dirigentes indigenistas, de ONGs y de la Iglesia Católica, quienes suelen postular la "vida en comunidad" como característica distintiva del pueblo kolla y referenciarla en cierta imagen idealizada del ayllu andino precolombino, en cuanto arquetipo de la convivencia armónica.

Estos principios configuran cierto sentido común sobre el 'deber ser' de la convivencia, pero en el cotidiano se revelan diferentes interpretaciones y lógicas de comportamiento de los vecinos. Las comunidades yaveñas, lejos de corresponderse permanentemente con grupos cohesionados y corporativos, se encuentran en continua redefinición a partir de las cosas que unen y enfrentan a sus miembros. Ante las tensiones entre miembros o familias, los vecinos apelan a sus interpretaciones y aplicación de esos valores a la disputa en cuestión, para validar sus puntos de vista y desautorizar a su(s) contrincante(s), en un intento de sumar adeptos a su causa. Una política de reputación o pequeña política, según el término acuñado por Frederick Bailey (1971, p.2) para diferenciarla de la política institucionalizada, fundada en juicios morales aplicados a las prácticas de los otros, sobre los que se (re)producen alianzas y enfrentamientos que imprimen cierto dinamismo y jerarquías morales en la sociedad yaveña.

Los yaveños también se reconocen y unen a través de otros principios de filiación, como ser religiosos (grupos católicos y evangélicos), agrario (Movimiento Campesino), étnicos (Red Kolla ${ }^{\underline{v}}$ ) o políticos (partidos políticos y "líneas" o facciones internas). Cada red de filiación recorta y aglutina un grupo de personas. Éstas participan simultáneamente de varias redes de pertenencia y entre pares pueden vincularse a través de más de un papel social. Este tipo de vínculo, denominado relaciones múltiples por Max Gluckman (1975, p.165), está ampliamente difundido en la zona y es característico de las pequeñas sociedades. 
La estructura social yaveña puede ser interpretada como un entramado de redes de filiación parcialmente superpuestas, a través de las cuales sus miembros se relacionan y diferencian de otros. La familia y la comunidad son redes sociales permanentemente activadas, en cuanto las otras (religiosas, agropecuarias y políticas) se accionan intermitentemente. Dada la movilidad espacial de los yaveños y los vínculos que establecen con personas residentes en otros territorios, ninguna de las redes mencionadas se circunscribe a la comarca, sino que la traspasan. La idea de sociedad yaveña sólo la acciono a los fines analíticos, pues no existe empíricamente como una unidad sociológica disociada del resto.

\section{La política, un universo inmoral}

En mis conversaciones con los yaveños, todos tuvieron una idea concreta y fundada sobre "la política” y "los políticos". Incluso cuando introducía el tema y afirmaban "no saber de eso", en el transcurso de la charla se revelaba que, más que un desconocimiento, estaba en juego la necesidad de explicitar la no pertenencia a ese ámbito social, justamente por conocerlo. A través de ese (des)conocimiento se afirmaba la opción por un distanciamiento con esa esfera social.

En una sociedad pequeña como la yaveña, gran parte de la población se (re)conoce y tiene algo para decir sobre los otros, en especial sobre "los políticos", pero no es para decirlo a todos, menos a un foráneo. Hablar de política personalizando, supone opinar sobre los funcionarios de la Comisión Municipal, con quienes es raro que no exista algún tipo de vínculo, directo o indirecto, sea en términos de confraternidad o enemistad. Tal vez por ello, los relatos eran fluidos y taxativos cuando se hablaba de "la política" en abstracto, un recurso retórico para opinar sin explicitar de quién se habla. Solo algunas personas públicamente identificadas con la facción "oficialista” o con las "opositoras” personalizaron sus relatos, para elogiar o condenar, el proceder de quienes asumían cargos "políticos”.

En los relatos de los yaveños, la categoría "política” suele estar caracterizada con un repertorio de calificativos y prácticas, entre las que destacan: "sucia”, “mentirosa”, “desigual”, “divide”, "hace pelear” y "tira para su gente, para su familia”. No parece ser exclusivo de Yavi atribuirle a la política sentidos moralmente negativos, también fue observado en otras localidades rurales en Quebrada de Humahuaca por Guillermina Espósito (2009), y en barrios del conurbano bonaerense por Sabina Frederic (2004) y Javier Auyero (2001).

Cuando indagaba sobre los motivos de esa percepción era común que mis interlocutores remitieran a las promesas de campaña incumplidas. Gran parte de los yaveños asocian de inmediato "la política" a la campaña electoral y a las prestaciones que ocurren entre los candidatos y sus potenciales electores. "Para ser político, primero hay que ser embustero”, sentenció una anciana para graficarme que el engaño regía la promesa de ayuda que "los políticos" realizan en la campaña electoral. Interpretan que en "la política" domina un tipo de intercambio diferente al practicado en el ámbito familiar o comunitario.

En una conversación con Camilo $\underline{6}$, en la que me explicaba el funcionamiento de su comunidad, intermitentemente refería a la “intromisión de la política”, por lo que solicité su percepción sobre ella:

Mire yo... yo no entiendo de política, pero yo veo que son partidos que vienen... como ser, un partido dice: "yo soy político. ¿Por qué? Porque yo soy peronista”. Viene otro y dice: “yo soy político. ¿Por qué? ¡Ah, no! ¡Yo soy radical!” Bueno, eso es lo que yo le llamo política. Ahora, mire, yo no hice un curso de político, pero la política es muy roñosa, ¿no? Disculpe que tenga que decir así, porque es jodida la política. Es que la política a veces nos hace pelear. También eso es mucho que se entrepone entre nosotros, porque uno viene "yo soy peronista", el otro viene "yo soy peronista” [de otra facción] entonces como que el peronismo ha sido un líder en esta comunidad y 
toda la vida ha tenido su poder. Bueno, después de ahí, fueron naciendo otros partidos chicos. Uno va viendo a dónde va a poder ir, con quién va a ir. Y bueno, nosotros [se refiere al grupo comunitario] tenemos mucha emoción a veces antes de la política, de trabajar, hacer y cuando viene la política ya nos olvidamos porque nos volvemos todos políticos. Entonces eso nos hace pelear, que no estemos unidos, quizás eso nos divide mucho, mucho, la política es muy jodida.

En el relato, "la política” es representada como una entidad genérica, que puede expresarse en las cosas, en representantes de partidos políticos o en determinados momentos del año, constituyéndose en una categoría polisémica.

"La política” puede expresarse en las cosas, pero no todas las cosas son "políticas”. Existe una esencia en "la política” que torna las cosas "políticas”. Camilo siempre le adjudica una valoración negativa y la percibe como algo externo o, mejor dicho, ajeno, con alto poder de influir, atravesar límites o, más ilustrativamente, penetrar y contaminar lo que ontológicamente no es político. Algo percibido como nocivo, pero que, por algún motivo, atrapa y encanta a las personas.

Las personas pueden ser "políticas". Para Camilo y para la mayoría de los yaveños, la esencia de la "política” es lo que emana de los partidos políticos. Una persona es o comienza a ser concebida como "política” cuando actúa en favor de un candidato o funcionario político. En esa definición, no es tan importante estar afiliado a una estructura partidaria -de hecho, la inmensa mayoría de los yaveños está inscripta en alguna-, sino orientar sus acciones a favor de alguna de las facciones políticas. Sin embargo, no es común que las personas se asuman como "políticas”. El propio Camilo candidato de una facción opositora en las elecciones anteriores tampoco se presentó como tal. A excepción de quienes ocupaban cargos en la Comisión Municipal y de los dirigentes políticos tradicionales, nadie asumió el papel de “político”. Quienes lo hicieron enfatizaron que eran diferentes, exaltando sus cualidades morales y se atribuyeron la misión de 'higienizar la política', por medio de orientarla en beneficio de los que más necesitan. Es entendible que, en el resguardo de su reputación, nadie desee ante los ojos de sus pares y de un foráneo vincularse $a$ priori a un ámbito social considerado inmoral.

Asociada a las prácticas, la categoría "política” adquiere todo su poder de sentencia cuando es utilizada como adjetivo: cuando algo se hace de manera "política”. Pero, cuándo una cosa o una práctica es "política”. Como explicó Camilo: “dar políticamente es cuando hay algún beneficio que [el político] da para su gente, para su partido". "El político" es visto como alguien con el poder de penetrar, influir y contaminar otros dominios sociales. Eso está asociado al hecho de que a "la política” se le atribuye una temporalidad y una espacialidad dinámicas y correlacionadas.

En el relato de Camilo está presente la temporalidad de "la política", algo que llega en determinado momento, tienta a las personas e invade lo que no es político, lo que es puro, unido y moral, para fracturarlo y enfrentarlo. Vista así, "la política" se constituye en un ámbito social cuya lógica de acción es por excelencia agonística. Si en el ámbito familiar y en el comunitario se trabaja intensamente por producir unión y concordia, en el político sucede lo contrario. Conforme observan Palmeira y Heredia (1997, p.167), la campaña electoral consagra el tiempo de la política, caracterizado por la lucha entre facciones que disputan cargos. Es preciso que el conflicto sea llevado a su límite para que la facción política pueda emerger y ganar visibilidad. La unión, en todo caso, tiene sentido al interior de la facción, pero entre miembros de facciones opuestas se busca exacerbar diferencias, producir el mayor distanciamiento posible, afectar la reputación del otro, a fin de consagrarse como única alternativa posible. Sin disputa la política parece no tener sentido.

La percepción moralmente negativa que los yaveños tienen sobre la "política" no significa que la nieguen o se mantengan al margen, por más que algunos lo exalten en sus relatos. Más bien refiere al modo cauteloso con el que se relacionan con un ámbito social percibido como "sucio" y disruptivo, pero necesario, no sólo 
en la (re)producción económica, sino también social de los sujetos.

Otro aspecto que llamó mi atención fue la coherencia de sentido sobre "la política” y "los políticos" que encontré entre los habitantes y los representantes políticos yaveños. En los relatos de ambos se apreciaban los mismos sentidos delineados en los párrafos anteriores. Mientras los electores se referían a la dinámica de la política local, "los políticos" atribuían esas prácticas a los dirigentes provinciales y nacionales, que "no cumplían” y se “olvidaban” de los yaveños, adjudicándose una posición -de ‘víctimas’- homóloga a la asumida por los electores.

Si existe una visión escéptica de "la política" es porque se la construye en oposición a un ideal. Indagada sobre su idea del 'buen político' Camila, mujer adulta, presidenta de una "comunidad” e integrante de la “oposición”, respondió idealizando a un antiguo dirigente del lugar: "él no miraba en quién habíamos votado, él repartía a todos por igual, a todas las comunidades, te ayudaba...”. En sintonía con esa perspectiva, Narina ${ }^{7}$ afirmó: "un político es bueno cuando realmente se preocupa por la gente. Trata de trabajar, de ayudar, o sea, está ahí con la gente. El intendente, para mí, es un buen político porque siempre está. Cualquier problema que uno le plantea no le dice que no, le trata de solucionar”. Y, ciertamente, Narina accedió a un puesto de trabajo fijo en la Comisión Municipal, de ahí que personalice y reconozca la gestión del comisionado. Un fenómeno semejante es evidenciado por Auyero, quien observa una relación positiva entre la percepción de vecinos de un asentamiento del conurbano bonaerense sobre el funcionamiento de la política y su proximidad al centro de distribución de recursos (2001, p.167).

Fue elocuente que en ninguno de los relatos colectados se definió, significó o relacionó la política con ideologías, conforme se expresan en las plataformas de los partidos políticos. Para los yaveños la función de la (buena) política gravita en "ayudar a la gente necesitada”. En una pequeña sociedad donde gran parte de las familias enfrentan dificultades para garantizar su subsistencia, toda persona que se encuentre en 'posición de dar', por tener acceso a recursos propios o de las instituciones públicas, tiene una obligación moral ante quienes "tienen necesidades". Los valores de igualdad y de unión configuran principios de comportamiento éticos, "darle al que más necesita” o "dar parejo”, según la disponibilidad de recursos, definen modos legítimos de la gestión pública. Esos principios son contrapuestos a "darle a su gente” o "a su familia”, la lógica que adjudican al modo de distribución que rige en la (mala) política. En función de lo expuesto, es entendible que con insistencia los políticos manifestaran que su vocación era "ayudar a la gente”. Sobre la dádiva en la política retornaré más adelante.

En Yavi, la inmensa mayoría de los pobladores categoriza como población objetivo de los programas sociales y se perciben como legítimos receptores de los recursos que se distribuyen desde la Comisión Municipal, pero éstos nunca alcanzan para satisfacer a todos. Es sabido que las personas piden "ayuda” para acceder a los beneficios de un programa o, más anhelado aún, a un puesto de trabajo. Esas iniciativas rara vez son relatadas por dadores y receptores, pues las gestiones para beneficio individual o familiar dan lugar a rumores; solo el pedido de ayuda para "beneficio comunitario" es digno de ser relatado. A través de los intercambios que operan en los vínculos políticos, no solo circulan bienes materiales, sino también simbólicos, por medio de las valoraciones y reputaciones que se construyen en torno a las prácticas y a las personas.

La delimitación y definición de "la política” no se agota en el bosquejo delineado hasta aquí. En los últimos años, la noción "política social” o "política comunitaria” comenzó a ser utilizada por técnicos de MINK’A y por dirigentes del Movimiento Campesino, para reconocer y valorar su práctica como "política” y contraponerla a la política tradicional. En la definición de una de sus dirigentes, la "política social es poder mejorar con las personas, con las comunidades". Lo distintivo radicaría en el "con”, que brindaría protagonismo a la gente, en oposición al "para”, que usan "los políticos”, presentando los recursos públicos 
como favores personales. De ese modo, buscan expresar e introducir una práctica política diferente, basada en los ideales de "igualdad”, “participación”, “representación” y “consenso”, que constituye el modelo de "democracia participativa" que proponen para la comarca y que converge con el modelo de comunidad que buscan consolidar. Su opuesto sería la "conducción autoritaria”, que interpretan opera en las organizaciones políticas y religiosas. En la asociación de esa 'otra forma de hacer política' con un dominio social asumido como moral, el comunitario, hay una intención de diferenciarla y jerarquizarla ante la política partidaria o tradicional.

Hasta aquí he graficado cómo los yaveños perciben, se refieren y posicionan ante la política cuando la objetivan como algo abstracto. Nótese que en el pensamiento y en las narrativas la política emerge cosificada, es decir, como un dominio autónomo y específico, diferenciado y en oposición a la familia, a la comunidad y a las organizaciones sociales y religiosas. En las próximas secciones abordaré cómo experimentan en la práctica la política, tratando de evidenciar la distancia existente entre la dimensión imaginaria y la vivida y los factores que explicarían ese fenómeno.

\section{Transformaciones institucionales y cambio en las prácticas políticas}

Desde el retorno de la democracia en 1983, en Yavi han ganado las elecciones candidatos del Partido Justicialista o "peronistas”. En los primeros años, el peronismo disputaba las elecciones con el otro partido tradicional, la Unión Cívica Radical, pero en las décadas siguientes los votos cosechados por los "radicales" no superaron el 12\%. Las elecciones pasaron a dirimirse entre “líneas” peronistas.

Aproximadamente el $60 \%$ de los electores yaveños está afiliado al Partido Justicialista y se sienten “peronistas”, incluso varios dirigentes opositores. Hasta 1991, la arena política yaveña estuvo dominada por un 'hombre fuerte’ de La Quiaca quien, a través de su referente en Yavi, movilizaba a la población para los comicios. Camila recuerda:

Llegaba [el día de] las elecciones, mandaban los autos [a las comunidades] y... “iiiVamos!!!” No hacían reuniones, ni venían a charlar con la gente. Nada de que "ustedes me van a apoyar...”, porque él era el único. No había otro más, nunca había otro más. Nosotros íbamos callados y nos daba el voto y listo, votábamos.

Pocos fueron los relatos respecto de la vida política de esa época. "La política" en esos años siempre fue presentada como un asunto de "gente de afuera" y unos pocos residentes de "el pueblo". En "el campo" la campaña electoral se restringía a la semana o incluso al día de los comicios. En el relato de Camila es taxativa la imagen de sumisión y obediencia de los yaveños ante la autoridad política. A la distancia, es difícil corroborar si se corresponde con aquella cotidianeidad. Su significado analítico reside en su percepción de cómo era la política a la luz de lo que es hoy. Nos brinda un 'negativo' de su idea de lo que es "la política” en la actualidad. Ese registro no es exclusivo de ella. En las conversaciones sobre la política que tuve con los yaveños, era elocuente cómo sus relatos se estructuraban en torno a los circunstanciales de tiempo. El "antes” y el "ahora” emergían como mojones en el tiempo, que demarcaban y objetivaban la percepción que se tiene de los cambios que están operando.

Los cambios en las prácticas políticas están asociados a transformaciones institucionales en el sistema político. En 1986 se reformó la Constitución provincial y la definición del comisionado municipal pasó de ser atributo del gobernador a delegarse en el voto directo de los pobladores. Otro cambio significativo fue la implementación, entre 1991 y 1999, del sistema electoral conocido como "ley de lemas” o "doble voto simultáneo". En las elecciones generales, cada "lema” o facción de un partido político podía presentar lista propia y competir contra las otras para dirimir el candidato partidario. Al mismo tiempo, los lemas de un 
partido político suman sus votos en la disputa de cargos contra otros partidos. Ambas transformaciones favorecieron la postulación de pobladores locales para cargos públicos, pues ya no se dependía únicamente del aval de un dirigente provincial, el apoyo de los electores ganó prominencia. El aumento de candidatos locales favoreció el involucramiento de la población en las disputas electorales. El "campo", donde se encuentra el mayor porcentaje de electores, ganó relevancia en la campaña electoral.

Las transformaciones institucionales no explican por sí solas los cambios en las prácticas políticas de los yaveños, en especial en lo que respecta a la emergencia de nuevos sentidos y modalidades de vinculación y comportamiento. En el marco de la actualización de la cuestión indígena, la labor realizada por los dirigentes de las organizaciones sociales también puso en valor lo comunitario como instancia de participación y organización, patrocinando el comportamiento corporativo de sus miembros, aunque no siempre lo consiguieran.

Uno de los hechos emblemáticos que evidencia la creciente penetración de lo comunitario en la arena política es el Consejo Consultivo de Yavi (CC), que operó entre 2002 y 2009 y recomenzó en 2012. En 1999, los técnicos de MINK'A convocaron a los pobladores a una serie de talleres sobre democracia participativa y ciudadanía para reflexionar sobre el papel del Estado y los derechos y obligaciones de los ciudadanos. Apuntaban a cambiar la lógica de vinculación con los representantes políticos, para que asumieran "un papel activo y propositivo" en la formulación e implementación de políticas públicas. El ciclo culminó en la creación del CC, un ámbito de convergencia de representantes de las comunidades, para informarse, controlar y proponer acciones al comisionado municipal, con vistas a mejorar su gestión y trasparentar la asignación de los programas sociales. Así, los representantes de MINK’A produjeron una nueva institucionalidad donde ejercer, legitimar y contraponer la "política comunitaria" a la "tradicional”.

La nueva instancia fue resistida por las autoridades municipales por "inmiscuirse en sus asuntos”, pero acabaron por aceptarla. El funcionamiento del CC se estructuró en torno a una reunión mensual, rotativa por las comunidades, presidida por un dirigente del Movimiento Campesino y a la que estaban convocados representantes de la Comisión Municipal y los presidentes de las comunidades indígenas. A través del CC los pobladores yaveños incrementaron su involucramiento en la gestión municipal y operó un cambio en la temporalidad y espacialidad de la política, pues la dinámica de reuniones intermitentemente desplazó a la política del edificio de la Comisión Municipal a las comunidades.

En la experiencia del Consejo Consultivo se objetivan dinámicas que se encontraban en curso en la comarca y que se cristalizaron en esta nueva institucionalidad. No sólo evidencia la mayor injerencia de las comunidades en la vida política yaveña, sino la forma en que la política se vio permeada por lógicas, valores, lenguajes y modos de vinculación y participación propios del modo de vida comunitario. Un análisis en profundidad del proceso, conforme analicé en otros artículos (Cowan Ros, 2013b y 2014), posibilita evidenciar el papel que tuvieron los técnicos de MINK'A en difundir otros sentidos y modos de hacer política, pero también los límites y resistencia que encontraron para transformar totalmente los modos de involucramiento de los yaveños.

Como observó Camila y muchos otros lugareños, “las cosas ya no son como antes”; algo está cambiando en Yavi. Los dirigentes políticos provinciales y regionales pierden centralidad en la arena política yaveña ante los pobladores locales, al igual que el "pueblo" ante las “comunidades”ㄹ. Entre 1983 y 1991 los comisionados municipales fueron designados por el Gobernador, a propuesta de un dirigente de La Quiaca. En 1991 irrumpió en Yavi un nuevo dirigente local que a partir de sumar adherentes en las comunidades consiguió construir una "línea peronista” y hegemonizar la Comisión Municipal hasta la actualidad. Uno de los indicadores del cambio es la existencia de dirigentes políticos de las diferentes facciones en cada comunidad y su rotación en los cargos de la Comisión Municipal. Si bien las cosas cambian, no ocurren 
necesariamente en el sentido planificado por los técnicos de MINK’A. Para comprender los límites con los que éstos lidian debemos comprender las vivencias y modos de vinculación, de dar y de recibir que experimentan los yaveños en el tiempo de la política, momento en el que se objetivan y explicitan muchos de los códigos y normas que regulan la política local.

\section{Tiempo de la política: modos de vinculación, de dar y de recibir}

El tiempo de la política se preanuncia con los 'mapeamientos' recíprocos que realizan los dirigentes, para sondear sus ambiciones de candidatura. Es un momento de tensa calma, pues está en juego la renovación y/o ruptura de alianzas. Esa reservada negociación ocurre ante un público expectante que, lejos de asumir un papel pasivo, influye en la configuración de posiciones, a través de los rumores que hace circular, que tienen por blanco las reputaciones y delatar las intenciones de los aspirantes. Quienes sientan chances de conseguir el "apoyo” de los líderes locales y/o provinciales, lanzarán su candidatura en las elecciones primarias, para lo cual tendrán que sumar adhesiones. Así, irrumpe una nueva dinámica en las comunidades, que es conocida y esperada, pero no siempre anhelada.

En todas las elecciones además de representantes para la Comisión Municipal, se eligen candidatos para las instancias provinciales y/o nacionales, pero para gran parte de los yaveños poco interés tiene la figura de estos últimos. Existe escaso conocimiento de esos líderes políticos, de sus partidos y programas de gobierno y de las funciones asociadas a los cargos que compiten; es la figura y reputación de los candidatos locales la que fundamentalmente está en juego. Entre los dirigentes oficialistas yaveños, existe cierto conocimiento y preferencias respecto de las facciones partidarias provinciales. Sin embargo, manifestaron no tener mucha opción al momento de encuadrarse, pues un distrito pequeño como el yaveño $(0,2 \%$ del padrón electoral provincial) únicamente puede apoyar a la "línea” que se prevé gobernará. Situarse del lado del probable perdedor, opción 'residual' de los opositores, solo condenaría al candidato y a la comarca al ostracismo.

Para lograr la adhesión de los electores, los candidatos locales visitan las comunidades. Procuran tener al menos un referente en cada una, quien a su vez moviliza sus redes de pertenencia y convoca a una reunión, en un marco de confraternización e intimidad. Genera cierta incomodidad entre quienes no lo reconocen como un allegado, pues si bien es una visita esperada, es reconocida como interesada. Se espera que los candidatos lleguen, pues no ser visitados supondría ser ignorados, lo que limitaría la posibilidad de solicitar “ayuda” durante su gestión. Pero es percibida como interesada, ya que se sabe que el propósito es comprometer el voto de los vecinos. Para los parientes y amigos del candidato es un evento emocionante y festivo, al que convergen para celebrar y apoyar.

Con esas visitas se oficializa el tiempo de la política en la comarca. La programación, así como la participación o autoexclusión de los vecinos en las reuniones, es una forma de administrar el ingreso de "la política” en la comunidad, para evitar peleas. Asistir puede significar la simpatía por el candidato o, cuanto menos, que no se es "opositor". Es un principio de adhesión pública, pero con cierta discreción. La mayoría de las personas evita exaltar su filiación por tal o cual candidato. Interpreto que eso ocurre porque en un ámbito social donde "la política” y "lo político" son moralmente cuestionados, vincularse con ese dominio es tolerado siempre que no sea exaltado. Se consiente, pues se reconoce que todos necesitan ayuda y/o tienen sus preferencias, pero se reprueba cuando es alardeado, se promueven enfrentamientos o se utiliza para un beneficio individual desmedido.

Fue llamativa la frecuencia con la que varias personas me respondieron "hay que respetar el voto de los otros", cuando interrogaba si intentaban unificar el voto como comunidad. "Respetar" significaba no cuestionar, no interpelar, e incluso, no debatir sobre a quién votar, cuando se sabe que existen diferentes preferencias y vínculos. Era elocuente el contraste entre la libertad para criticar a "la política” y a "los 
políticos” genéricamente y la veda que se imponía cuando se hablaba de las personas que encarnaban esos papeles. Debatir sobre candidaturas supone opinar sobre la cualidad moral de las personas y, por extensión, sobre la de su grupo de pertenencia, probablemente algunos de los vecinos de la comunidad. La categoría "político", con la que los medios de comunicación y los cientistas sociales clasificamos y, por medio de ese acto, fragmentamos y abstraemos solo una faceta de la vida de esas personas para la opinión y/o el análisis, no coincide con la forma como los yaveños las siguen reconociendo. Difícilmente el candidato que visita una comunidad sea percibido únicamente como "político". Suelen tener otras referencias a partir de las cuales reconocerlo y situarlo en sus redes de pertenencia como un "familiar", un "vecino", un "compadre”, un "amigo", un "hermano de fe" u otro vínculo que se mantiene en forma directa o a través de terceros. Esas relaciones pueden ser en términos de concordia o conflictividad, pero me interesa destacar que en una sociedad pequeña difícilmente la figura del "político" se anteponga a los vínculos primarios sobre los cuales se estructuran las relaciones sociales. Existen pocas posibilidades que "la política" opere como un universo impersonal o disociado del resto. La noción de relaciones múltiples ilumina no sólo un fenómeno estructural de las relaciones sociales, sino también una vivencia que interviene en los modos de vinculación y en las formas como se da y se recibe en la política.

En función de lo anterior, se entiende por qué las características atribuidas a la política en abstracto distan de cómo la vivencian cuando está personalizada. Esto aporta a comprender por qué el escepticismo generalizado ante la política no se corresponde con el bajo porcentaje de votos en blancos, en torno del $5 \%$.

En la comarca yaveña, como en otros lugares del país y del mundo, el tiempo de la política es propicio para dar y recibir cosas. Es frecuente y esperable que en la producción de las adhesiones de los votantes a los candidatos, intervenga la circulación de bienes, algunos ostentados públicamente como obsequios (hoja de coca, bebida y comida, viajes en remise, etc.) y otros ofrecidos en la intimidad como "ayuda" (materiales de construcción, jornales de trabajo, etc.). Más allá del valor material de los bienes o servicios ofrecidos, estos siempre cargan consigo una representación, pues pretenden significar la generosidad del candidato, una forma de augurar lo que será su gestión.

Conforme observa Javier Auyero, gran parte de los autores que analizan ese fenómeno, haciendo un uso acotado de la potencialidad analítica de la noción clientelismo político, simplifican el sentido de esos intercambios al 'ecuacionarlos' a la fórmula "compra de votos”, como si fuera una transacción mercantil (2001). En versiones menos economicistas, que pretenden evidenciar las relaciones de dominación en la política, es común que se (re)presente a las partes caricaturizando al político como un actor cínico y manipulador, que concentra el poder ante un electorado dividido, alienado, pasivo y despojado de toda agencia y/o papel en la configuración del vínculo. Cuando se les otorga agencia es para destacar una anomia cultural, derivada de la condición de pobreza.

Esos enfoques, si bien objetivan aspectos de la circulación de prestaciones en el tiempo de la política, son limitados en su capacidad explicativa de los fenómenos observados. No es casual que las categorías elegidas por los yaveños para designar y retratar el sentido de esas prestaciones sean: "ayuda [a los electores] por apoyo [al político]". Tampoco es casual que ese lenguaje no mercantil, con cierta carga ética y moral, haya sido registrado por Palmeira y Heredia (1997) en comunidades rurales brasileñas y por Javier Auyero (2001, p.134), Julieta Quirós (2011), Virginia Manzano (2013, p.165), entre otros/as, en asentamientos y/o organizaciones del Gran Buenos Aires. Recuperando los aportes de la teoría sobre el don de Marcel Mauss, estos autores/as convergen en pensar esas transacciones como intercambios, que operan en un contexto moral, que rige la obligación de dar (“ayudar”), recibir y retribuir (“apoyar”). Los bienes o favores ofrecidos siempre adquieren un sentido mayor a la cosa intercambiada, pues conllevan cierta carga simbólica y afectiva. 
El aporte de mi análisis a la comprensión de los modos del dar y recibir en la política, refiere a que la “ayuda” no es vivenciada de igual manera por los sujetos y, en consecuencia, no adquiere el mismo sentido y formato en todos los casos. Comprender el sentido y las lógicas que alcanzan los intercambios en el tiempo de la política supone, por un lado, conocer la forma en que las partes se reconocen y, por otro, situar ese intercambio en un ciclo de prestaciones que puede operar con anterioridad y/o posterioridad a la campaña electoral.

Entre los electores que "apoyan” a un candidato, se pueden diferenciar tres tipos de vínculos: i) los establecidos entre el candidato y su círculo más próximo (grupo doméstico, parientes, compadres, etc.), ii) entre el candidato y su red de pertenencia más amplia (vecinos, “amigos”, etc.) y iii) entre el candidato y personas con los que no existe un vínculo directo, es decir, preexistente a la campaña.

En los dos primeros casos, los seguidores no ven al candidato apenas como un "político": ante todo lo ven como un padre, un hermano, un tío, un compadre o un colega que se lanza a la "política”. La "política” pasa a ser una instancia más de su cotidiano en la que se brindarán apoyo mutuo, pues los lazos primarios son un presupuesto y crean ciertas expectativas morales respecto al comportamiento solidario cotidiano. No se está intercambiando un voto por ayuda. Se está (re)produciendo el vínculo, que tiene importante carga simbólica y afectiva, en el marco de un ciclo de prestaciones. Incluso, algunos de ellos sentirán como propio el proyecto de la candidatura y aportarán dinero, trabajo e incluso su propia reputación.

Ese tipo de intercambios puede ser interpretado como relaciones recíprocas que, conforme Marshall Sahlins (1972, p.193-194), será más difuso o más balanceado según el grado de proximidad social del vínculo entre las partes. Irá de la ayuda incondicional que le brinda un padre o madre a su hijo que se candidatea, a la demanda de apoyo que le hará un candidato a un "amigo" que benefició con algún cargo o programa social durante su gestión o alguna otra prestación por fuera de la "política”. En el primer caso los intercambios son menos calculados, ocupando los elementos simbólicos (afecto, lealtad, identidad, etc.) un lugar significativo en el móvil de las personas. En el segundo, el cálculo del equilibrio del intercambio adquiere relevancia en el comportamiento de las partes.

Pero no todos los yaveños tienen vínculos establecidos con los candidatos o con los dirigentes políticos, ni todos los candidatos tienen alguna gestión en su haber a partir de la cual reclamar "apoyo" por algún favor realizado. Cuando no existen vínculos, las prestaciones que operan durante la campaña electoral pueden ser fundacionales de un lazo. El no reconocimiento de las partes como pares puede dar lugar a que el intercambio adquiera trazos de 'negociación', pues se asume que opera en el terreno de "la política", aceptándose las reglas del juego. Comencé a delinear esa idea cuando conversé con Caetano, un jornalero y agricultor escasamente vinculado a la política. Indagado respecto de cómo veía la campaña electoral, manifestó que no le interesaba y agregó:

[...] porque toda la vida te prometen cosas y al final no cumplen. Así que... Viste que ahora... ¡Qué se yo! Antes te daban una bolsa de mercadería, a los abuelos les daban una bolsa de mercadería, un poco de coca y “iya... vení!” Así ganaban la elección. Ahora con nosotros, en cambio, ahora no. Si viene alguien voy a recibir, total es normal, pero yo creo que es parte del curro... Vos opinás para quién te parece mejor. No soy fanático de la política.

En el relato son especialmente reveladores los términos "normal” y "curro" para comprender la vivencia de Caetano de la política. Recibir algo que ofrece un "político” es "normal”, por ser una práctica generalizada y tolerada. Es "normal” porque lo que ofrece el "político" siempre es dado como un obsequio, una "ayuda”, y los regalos no se rechazan. Es "normal” porque es deseable que el que está en una mejor posición social dé al que está en una situación desfavorecida. Sin embargo, ese presente dado entre agentes sin vínculos preexistentes y en el tiempo de la política, parece no tener siempre la fuerza para comprometer, como tienen 
las prestaciones entre allegados, debido a que ocurre en un contexto ambiguo. Genera cierto compromiso, pero acorde a la percepción que se tenga del otro y del contexto en cuestión. Como enuncia Caetano, "es parte del curro", recibir sin obligarse a votar por el candidato. Interpreto que "curro" refiere a picardía, referenciando la lógica del juego político. Pues, así como existe la idea de que el "político" promete, pero no cumple, lo que puede ser interpretado como 'robar un voto' e incluso la confianza del elector, algunos yaveños comienzan a 'jugar y a pagar con la misma moneda'. Empeñar la palabra tiene un valor moral importante y está relacionado con la honra de la persona, pero empeñar la palabra a alguien que no tiene, carece de sentido. Habla de la ingenuidad de la persona, tal como percibe a sus "abuelos”, tal como Camila retrató la política de "antes”.

Caetano recibe de todos, pero vota -“opina”- solo por uno. Lejos de ser sancionado moralmente ese proceder, parece ser valorado como una virtud, digna de ser ostentada y relatada. Es una forma de distanciarse del estereotipo de "sumisión" e "ignorancia" atribuido tradicionalmente a los puneños, para comunicar que se aprendió a lidiar con los políticos. Como dice un dirigente local: "la gente abrió los ojos” y parece que ahora las personas ven qué pueden obtener de "los políticos". La actitud negociadora de los electores es otro de los cambios que los yaveños perciben en su comportamiento, y que retrata el "ahora" que ve Caetano.

Muchos relatos versaron sobre la "mentira” como práctica generalizada en el tiempo de la política. Por mi parte, opto por accionar la idea de 'especulación', para referir la lógica de intercambio entre quienes no se reconocen como pares en la campaña electoral. Pues "los políticos" prometen cosas que no siempre son cumplidas y sus potenciales electores insinúan adhesiones que no siempre se verifican en las urnas. Fue en la intimidad de una charla, que Orestes me reveló el juego táctico que puede operar.

- ¿Cómo son las campañas electorales? ¿Cómo hacen los políticos?

- Y bueno, generalmente... ahí están re blanditos los políticos.

- ¿Blanditos en qué sentido?

- En el sentido de que bueno “vení, te voy a invitar una cerveza, te voy a pagar un almuerzo...”. Están buenitos, "vamos a hacer esto, vamos a hacer aquello" y por ahí son muchas promesas también. Nosotros ya lo sabemos a eso, pero entre esos tenemos que elegir... [...]

- ¿'Sabés que los políticos dicen que ellos no dan nada cuando van a las comunidades? Yo lo preguntaba en la campaña electoral: “¿y cómo es una campaña?”. "Vamos y hablamos con la gente”. “¿Pero ustedes dan algo?”. "No, nosotros no damos nada, no nosotros ya cambiamos, eso era antes, nosotros no damos nada a la gente..."

- Siempre dan...

- ¿Pero qué dan? ¿Más así para comer, un asado, coca?

- Dan coca, un almuerzo, una gaseosa, unos vinos y hasta te hacen "machar” [embriagar].

- ¿Y ustedes les han hecho pedidos como comunidad en época de campaña?

- Sí, les hemos apretado fuertemente. Así como yo te digo, les hemos apretado dos veces. Creo que les hemos apretado a los candidatos, porque les hemos visto que económicamente estaban bien, por eso les hemos apretado.

- ¿Qué les han pedido?

- Una vuelta les pedimos una bomba: “Queremos ya la bomba”. La bomba costaba en ese tiempo mil y alguito, ponele 1.200, y nosotros sabemos que un comisionado puede ganar mil y algo, 1.500, entonces le decíamos: “Jugate un mes de trabajo acá”. “iiiNo!!!, ique es mucho!”. "Bueno, entonces no nos vengas a molestar...”. Y se arrepintió, se fue. Nosotros estábamos en una techada de casa y había un grupito de diez, te hablo techando la casa para un vecino. Ahí vino, nosotros le propusimos 
esto y como que no le gusto nada y se fue...

- ¿Cómo? ¿Él vino a proponerles otra cosa a ustedes?

- Él vino a proponernos que le ayudemos en la campaña: "Muchachos, yo quiero que me ayuden en esta campaña porque yo soy el candidato, les voy a dar esto...”. "No. ¡Pará! Nosotros queremos una bomba para el agua potable”. “¿Cuánto cuesta?” “Cuesta 1.200”. “¡Ah, no! Pero es cara, mirá si no gano!". "Pero nosotros te vamos a apoyar, nosotros somos 80 votantes, somos 80 votos que tenemos para vos, si vos nos das la bomba!". "No, pero y si los otros [de otras comunidades]...” . "Vos asegurate con aquellos, pero nosotros te estamos dando nuestra palabra que nosotros te vamos a apoyar. Si vos nos das la bomba, te vamos a apoyar todos". "No, que a ustedes no les creo...”. "Ah, bueno, si no nos creés...jAndate!”. Se fue, volvió como a las tres, cuatro horas y otra vez nos volvía a insistir. "Nosotros te pusimos la propuesta ¿qué más querés? [...] nosotros ya te pusimos lo que queremos, no nos insistas más, si vos no podés, bueno, déjalo que venga el otro [candidato] a ver si él puede...”. Y no le gustó... Y bueno, entonces vino nomás en un rato y dijo: "Bueno, está bien... ¿me van a apoyar?”, era ya faltando poco [para los comicios]. "Te damos una semana para que vos nos traigas la bomba. Si vos no nos traés la bomba en esa semana, con nosotros no contés. Ahora, si viene la bomba sí”. "Está bien, les voy a averiguar los precios y voy a traer la bomba”. "Bueno, entonces te apoyamos". Pasó una semana, no habrán pasado ya cuatro días y le fuimos a insistir: “¡Che! ¿Va a venir eso o no va a venir eso?”. “¡Sí!”, agarró y nos puso fecha. “¡Tal día yo estoy con la bomba ahí muchachos!”.

- ¿La fecha era antes de las elecciones?

- Antes de las elecciones. Y bueno, vino. Justo se hizo acá, en mi casa fue. La eligieron, no sé por qué... porque en ese tiempo yo era el presidente de la comunidad aborigen. Y bueno, yo puse mi condición y la gente me apoyó. Bueno, hicimos un asado acá, vinieron los políticos y nos trajeron la bomba. Nos entregaron en presencia de todos. "Bueno, bárbaro, te apoyamos, vamos con vos..."

- ¿La gente de la comunidad respondió?

- La gente de la comunidad respondió. Fue en la campaña de Tirso [2003].

- ¿Cuando fue la última campaña, la de 2005, apoyaron a Gorrión [correligionario de Tirso]?

- Sí, Gorrión...

- ¿¿De nuevo apoyaron todos como comunidad o cada uno votó como quería?

- Ya fue un poco medio individual, pero sí, lo apoyaron. Lo apoyaron porque... creo que vino dos veces acá, no vino más... Tenía buenas propuestas el chango. Yo lo apoyé, por ahí, un poco porque estaba con Tirso. Yo a Tirso ya lo tenía, más allá de político, lo tenía como amigo, somos medio amigos con Tirso. Entonces: "Che, vos sos mi amigo y él es mi otro amigo, no me juegues así [dijo Tirso]”. "Bueno, está bien, te vamos a apoyar”. Por ese tema que lo apoyé.

Al vivirse la contienda electoral en términos agonísticos, gran parte de los relatos remiten a enfrentamientos y disputas en los que está en juego el honor de los contrincantes. Es común observar en la reconstrucción de los hechos un sesgo a (re)interpretarlos y ajustarlos a la luz de los resultados finales. Se tiende a seleccionar y (sobre)valorizar la dimensión de la conciencia y del cálculo estratégico, minimizándose y/o excluyéndose los hechos fallidos o gobernados por las emociones. Por ello, el potencial analítico de los testimonios, lejos de referirse a la veracidad de los hechos, remite a aprehender las percepciones que están en juego sobre lo que son esas prestaciones en la política. Interesa captar lo que es pensable y decible; la subjetividad implícita en una narrativa donde se valoran los términos en que se debe negociar con los candidatos, pues evidencian las condiciones de legitimidad de esas prácticas en ese universo social.

La idea de negociación contenida en el relato está en consonancia con la expresa por Caetano y ganan fuerza explicativa si ambas son analizadas conjuntamente, aunque en la primera se grafique un proceder individual 
y en la de Orestes uno corporativo, próximo al deseado por los técnicos. Orestes no solo ilustra una de las formas en que pueden ocurrir los intercambios en política, sino también se explicita un ciclo de prestaciones, que evidencia la producción de un vínculo, y con él, la redefinición de los términos de los intercambios.

Tirso, el candidato, no es originario de la comunidad donde ocurrió la negociación. Es yerno del líder de la línea oficialista, miembro de una Iglesia evangélica y se lanzaba por primera vez como candidato. Contaba con su red de vínculos y la de su yerno, pero en ellas no se encontraba Orestes ni otros referentes de su comunidad, la más populosa del distrito, pero considerada “opositora”. Orestes contaba con cierta trayectoria de participación en el Movimiento Campesino y con capacidades para lidiar con la institucionalidad pública.

La aproximación de Tirso ocurrió en una "techada”, instancia colectiva de trabajo en la que se moviliza un grupo de pertenencia. En esa visita no programada, Tirso pretendía sondear al presidente de la comunidad, para sumar su adhesión. Arribó con bebida y coca para 'romper el hielo', pero ese año los vecinos tenían un grave problema de abastecimiento de agua potable. Las circunstancias favorecieron su comportamiento corporativo. Lo apremiante de la situación, la capacidad de objetivar las posiciones en la campaña electoral, sumado al coraje que brinda la asimetría numérica de las partes en juego, predispusieron a que Orestes, en su papel de presidente de la comunidad, sacara provecho de la situación y recolocase en términos de negociación lo que Tirso presentaba como confraternización.

“Los políticos” se encuentran en una posición de poder favorable ante los electores mientras ocupan un cargo en la Comisión Municipal, pues de ellos dependen para acceder a ciertos recursos públicos. Pero, en el contexto de las campañas electorales, la asimetría de poder entre las partes se reduce. Es el candidato quien invierte su dinero y reputación y depende del voto de los electores para recuperarlos. Cuando esa vulnerabilidad es percibida por los electores ("están buenitos, re blanditos”), y asumen un comportamiento corporativo, pueden sacar provecho e incluso afectar la percepción de la correlación de fuerza entre las partes. Orestes ofrecía 80 votos, que representaban el 13\% del electorado, y supo dimensionar su oferta en relación con la capacidad económica de su contrincante.

Llamativamente gran parte de la literatura sobre el clientelismo político, al incurrir en la cosificación del poder y adjudicarle su pose al político, ignora ese fenómeno, desconociendo las prácticas de resistencia que pueden implementar los electores, así como su papel en la configuración del vínculo, en la circulación de bienes y en el devenir de la política. Esa relación de poder, más allá de ser relativa es coyuntural, pues fluctúa en el tiempo. Durante la campaña los electores no son meros 'títeres' de los candidatos. Esperan recibir "alguna ayuda”, y no es raro que, cuando no existen lazos primarios, perciban al candidato 'mendigando votos'.

Ilustrado el escenario en el cual ocurrió la negociación entre Tirso y Orestes, tres elementos resultan relevantes para comprender su esencia: las condiciones de legitimidad, el papel del tiempo y el de la honra en la negociación.

A pesar de que el intercambio adquiriese características de una negociación, con trazos de regateo, considerada una práctica moralmente cuestionable, su legitimidad y, por lo tanto, la posibilidad de ser narrada, se relaciona con el contexto y con los bienes intercambiados. En el papel de presidente de la comunidad, Orestes negociaba en provecho de sus vecinos. No es el caso relatado por Caetano, en el que se recibe un 'obsequio'. Orestes "presionó” a Tirso para sacarle algo. Es raro que un yaveño relate un ejemplo de ese tipo, próximo a una extorsión, cuando es para beneficio personal, pero cuando es por el beneficio de todos, se transforma en una cualidad moral, especialmente si es presidente de la "comunidad".

Es expresivo el reparo que tuvo Orestes en aclarar: "vimos que económicamente estaba bien, por eso hemos presionado". Tirso se encontraba en posición de dar y se esperaba que compartiera. Por último, la 
negociación se llevó a cabo con un "político" en época de "campaña”. Un papel y un contexto que siempre despiertan sospechas. De este modo, la ambigüedad ética que envuelve toda negociación se justifica porque se le sacaba a un "político", que estaba en posición de dar, para beneficio de la "comunidad”.

En el relato, se percibe la tentativa de cada parte de gobernar el control del tiempo del intercambio. Especulan con que el otro inicie la prestación. Mientras Orestes está preocupado por obtener la bomba antes de los comicios, pues sabe que su cuota de poder se erosionará luego de esa fecha, Tirso intenta postergar la entrega para cuando asuma el cargo, ofreciendo a cambio su palabra. Ante la escasez de recursos, es común que los candidatos ofrezcan algo tangible durante la campaña, pero den a cambio su palabra, hasta acceder al cargo. Una especie de 'pagaré', respaldado por su honra, que funciona como garantía para los electores, a quienes se les demanda el voto efectivo. Pero “dar la palabra” en política, cuando no se está unido por otro vínculo, parece que ya no tiene mucho valor entre los yaveños. De ahí que Orestes haya condicionado el “apoyo” a la entrega efectiva de lo solicitado. Tirso cedió e inició la prestación. Ese año ganó las elecciones.

Si bien esa aldea obtuvo la bomba de agua, los miembros de las nueve restantes difícilmente podrían ofrecer un relato parecido. En concordancia con Auyero, observo que los recursos de campaña electoral de los candidatos nunca son suficientes como para satisfacer las necesidades de todos. Por eso, la producción de adhesiones no se explica solo por la distribución de bienes (2011). Durante la campaña electoral los candidatos proyectan su facción y movilizan adherentes fundamentalmente a partir de sus redes de filiación. Pero no siempre pueden accionarlas como una unidad. Por efecto de las relaciones múltiples, los electores integran diferentes grupos y a través de ellos pueden estar vinculados a más de un candidato. De ahí que en la solicitud de "apoyo" de un candidato, no solo se suman adhesiones, sino también se pone a prueba la lealtad de las partes y se revalidan los vínculos, siempre que las expectativas sean correspondidas.

Lo relatado por Orestes no refleja el comportamiento generalizado de los yaveños. Gana interés por ser un registro de las nuevas prácticas y visiones de mundo que comienzan a operar en la comarca y posibilita comprender la forma como se cristaliza lo que algunos denominan "política comunitaria”. Mi elección por la categoría 'negociación' para denominar esa modalidad de intercambio obedece a la necesidad de enfatizar el papel activo que asumen algunos electores en la circulación de bienes durante el tiempo de la política. Permite poner en evidencia la ambigüedad ética con la que viven esa práctica. Si bien en esos intercambios se acciona la retórica de la "voluntad de ayudar" y "el agradecimiento", el proceder especulativo de las partes es posible debido a que no se reconocen como integrantes del mismo grupo de pertenencia, por lo que tampoco se esfuerzan en ocultar su interés. La desconfianza mutua, al poner en duda la certeza de la retribución, hace que cada parte intente sacar algo del otro, ofreciendo lo menos posible. Ese tipo de intercambio se asemeja a la reciprocidad negativa propuesta por Sahlins (1981, pp.195-196); es la misma lógica que los políticos locales manifestaron percibir en su vínculo con los dirigentes provinciales. Hasta el día de los comicios esperan "la ayuda prometida", el dinero para la campaña. Si bien los candidatos nacionales y/o provinciales capitalizan los votos de los yaveños, la campaña se costea principalmente con el dinero y la reputación de los candidatos locales.

Si se analizan los diferentes tipos de intercambio relevados hasta aquí, puede verificarse que el modelo propuesto por Sahlins (1981, p.196) es aplicable al caso yaveño: "la distancia social entre aquellos que participan de un intercambio, condiciona la modalidad del mismo". Cuando la prestación ocurre entre pares vinculados por lazos primarios, tiende a ser menos calculada y más fundada en elementos simbólicos (afecto, lealtad, identidad, etc.), y cuanto menos fuertes son los lazos, el utilitarismo y la especulación ganan fuerza en el intercambio.

Incluso, en las transacciones con características de especulación, parece ser que las partes no siempre son inmunes al encantamiento contenido en la performance asociada -la idea de "ayuda"- a las cosas dadas. Es 
elocuente como Orestes, al final de su relato, redefine su vínculo con Tirso: “yo a Triso ya lo tenía... más allá de político, lo tenía como amigo, somos medios amigos con Tirso”. Parafraseando a Sahlins (1972, p.186): "si los amigos hacen favores, los favores hacen amigos” y en Yavi, la política es terreno fértil para producir "amigos" y movilizar favores y adhesiones. En la siguiente campaña, no hubo lugar para una negociación, pues entre amigos no se negocia. Tirso accionó su red de pertenencia en favor de su candidato, no precisó movilizar bienes materiales, sino simbólicos (afecto, lealtad, etc.) contenidos en el vínculo con Orestes.

Los compromisos y los lazos creados pueden ir más allá de los términos en que las partes negocian, lo que demuestra que no todo es fríamente calculado, como se exalta en los relatos. Aun cuando existe distribución de bienes, las transacciones o los elementos movilizados no siempre se restringen a lo pactado. Hay algo más en la cosa dada que llena de sentido las acciones y a las personas, compromete a las partes y contribuye a (re)producir vínculos. Orestes se siente en deuda por algo con lo que no se comprometió, pero el vínculo lo compromete. Si bien construyó el relato de esa experiencia en términos de un vínculo contractual, parece ser que su vivencia involucró mucho más que lo pactado.

En las conversaciones que tuve con los yaveños fue elocuente la frecuencia con la que la categoría "amigo" era accionada para referirse a lazos con personas asociadas a la política. La forma en que los yaveños viven la "amistad" en la política puede ser interpretada con la noción de amistad instrumental propuesta por PittRivers, en la que existe un interés en lo que cada parte puede dar. Pero el autor observa que ese vínculo "en situaciones de desigualdad material, crea una estructura de patronazgo, la cual enlaza la autoridad del estado, a través del poder económico de algunas personas, a la red de relaciones vecinales” (Pitt-Rivers, 1971, p.183). Retomando esa premisa, Wolf (1980) observó que esos vínculos, al estar imbricados con cierto contenido emocional, posibilitan disimular la asimetría de poder y, en consecuencia, la relación de dominación que envuelven. Esos aportes permiten reflexionar sobre cómo en sociedades pequeñas como la yaveña, donde no existen diferencias sustanciales de clase, "la política” puede ser un ámbito de producción de diferenciación social. Heredia (1996, p.64) observa que "el voto, si bien permite la retribución [del elector al político], no permite el restablecimiento de una relación entre pares que intercambian bienes del mismo tipo. En la medida que los políticos son elegidos con ese voto, ellos, cuando electos, aumentan su poder, lo que significa aumentar la desigualdad entre lo que pueden dar y lo que, de hecho, pueden recibir”. Así, se explica la (re)producción de las relaciones de dominación que se establecen en la política a través de la circulación de (contra)prestaciones. En Yavi, si bien se verifica un principio de capitalización diferencial entre quienes acceden a ocupar cargos en la Comisión Municipal, fundamentalmente a partir de la compra de vehículos y emprendimientos de servicios, al estar acotada a la escena local la proyección de los políticos yaveños (dado el escaso peso electoral de la comarca en el contexto provincial), se restringe con ella el acceso a otro tipo de recursos y, por consiguiente, el incremento de la asimetría de poder.

Interesantes aportes se han hecho en la academia argentina sobre la 'alquimia' que opera en los bienes públicos (planes sociales, cargos públicos, subsidios, etc.) cuando los políticos los transfieren a los electores, resignificando lo que es un derecho ciudadano en un favor personal y generando las condiciones de dependencia y dominio a través de la obligación de 'agradecer' y 'retribuir'. Auyero propone no solo centrar la atención en lo que se da, sino en cómo se da, en la performance asociada al acto de dar. No solo los mediadores políticos distribuyen recursos de la institucionalidad pública en nombre propio, presentando la cosa dada como "ayuda”, un "favor" que se brinda por voluntad propia, también asocian la continuidad de la cosa dada a su persistencia en el cargo (Auyero, 2000, p.135). Otros autores observan que lo que posibilita que el político y gran parte de sus seguidores vivencien al bien público como perteneciente al primero es que involucró su gestión (Boivin y Rostato, 2003), trabajo (Quirós, 2011, p.279) o lucha personal (Manzano, 2013, p.257). Pero, según observé en Yavi, las condiciones de reproducción de esas relaciones de 
encantamiento y dominación pueden encontrar sus límites cuando se percibe como injusta la distribución de los bienes, dando lugar a definir el acto como “apropiación”. Al revisitar la mirada escéptica de la política que tienen los yaveños, observo que no se cuestiona la distribución de bienes públicos como favor, sino las redes de distribución. Solo unos pocos dirigentes campesinos, que se reapropiaron de la visión de los técnicos, discernían como derecho los bienes públicos.

\section{Fin del tiempo de la política: vuelta a la comunidad moral}

Los "políticos" yaveños no se corresponden con el estereotipo del político cínico y manipulador, frecuentemente retratado en los medios de comunicación y en parte de la literatura académica. Las descripciones acerca del comportamiento de los representantes políticos suelen ser un tanto mecánicas cuando pretenden referir sus vivencias, motivaciones y prácticas, probablemente por sobrevalorizar la dimensión de la consciencia y el cálculo y por desnaturalizar su condición de persona y miembro de la sociedad en que vive. Esto último es producto de pretender interpretarlo únicamente a partir de uno de los múltiples roles que desempeña. Como miembros de esa pequeña sociedad, "los políticos” yaveños también se enfrentan a la ambigüedad de lidiar con las lógicas y éticas que existen en los diferentes dominios sociales. Tirso, en cuanto vecino del "pueblo” y "hermano" de una iglesia evangélica, al tiempo que se siente apasionado por el 'juego de la política', lo sufre por las presiones que pares y adversarios ejercen sobre él y por los propios dilemas a los que se enfrenta en el ejercicio de los papeles que asume:

Yo sufro para salir a hacer campaña. A mí me cuesta decir “dame tu voto”, porque cuando yo era joven sentía que a mí me hacían así, vienen, te ofrecen un montón de cosas y después no te cumplen. Lo único que quieren es llegar al poder y nada más. Aparte, es complicado el trato, a la gente no la conformás si hacés bien o si hacés mal. Para uno está bien, para otro está mal. El problema es que a veces se agarran con la familia. Si se agarran con vos, se agarran con tu familia. [...] Aparte yo soy evangélico y por esos principios decía: “¡No, no!” [al decidir si candidatearse]. Si yo sabía qué se hacía y lo que venía aprendiendo dentro de la Iglesia... Decís: “no, acá no voy a estar bien”. Hay injusticias que algunos no notan, que son muy injustas. Por decirte: "che, hermano, vos sos mi compañero, yo hice la campaña para que llegues vos, dame un empleo”. Cuando vos sabés que esa persona que te está pidiendo está mejor posicionada económicamente que aquel que no te votó pero necesita más. Pero yo decía: “¿y en esto cómo hago? Éste tiene razón, porque éste es el que me ayudó a llegar, pero el otro tiene razón porque necesita...” Pero si te agarrás de los principios bíblicos... Para serte sincero trato de armar un equilibrio, a veces no sé si le fallo a Dios o a la gente, trato de armar un equilibrio entre ambos...

El relato habla por sí mismo. En su definición de “(in)justicia” entran en colisión los valores y principios existentes entre los diferentes dominios sociales en los que interactúa. La dificultad de entrar en la política como individuo, sin involucrar a su familia; lidiar con la lógica agonística de la política en las aldeas, sin transgredir la lógica comunitaria; profesar su religión, sin sentirse infiel, son un conjunto de contradicciones que se expresan en el cuerpo de un individuo, que desempeña múltiples papeles sociales. Tirso manifiesta lidiar con esas ambigüedades, intentando alcanzar un "equilibrio” que, lejos de significar armonía, expresa ambigüedad y angustia, por sentirse en falta consigo mismo y con el resto. Si la "política" es terreno fértil para hacer "amigos”, también lo es para producir enemigos y no todos están preparados para lidiar con esa constante tensión y presión moral.

Fuera del tiempo de la política, "los políticos” continúan residiendo en la misma comunidad y viviendo bajo sus normas y sanciones, pues no ocupan posiciones dominantes en todos los ámbitos. La pequeña política, la política de la reputación, que se construye sobre la base de rumores y chismes, de comentarios y apodos, 
recupera el terreno del cotidiano y se constituye en una fuente de presión y de poder, que se ejerce contra los miembros de la facción ganadora, para que cumplan sus promesas de campaña. Sabedores de que los funcionarios tienen cierto control sobre los recursos públicos y un ingreso económico superior a la mayoría, son blanco de las solicitudes de ayuda económica de sus pares. Parte de sus electores tienen en su poder "la promesa de ayuda” ofrecida en la campaña, lo que es asumido y ejercido como un derecho para demandar apoyo en la Comisión Municipal. Por su parte, los parientes, vecinos o “amigos” sienten el derecho legítimo a solicitarle ayuda a su par. El político que se encuentra ejerciendo un cargo se enfrenta a un continuo dilema y desgaste moral. Negarle ayuda a un pariente o vecino supone transgredir un presupuesto moral y poner en riesgo la continuidad de un vínculo, ayudar a un pariente con recursos públicos supone presentarse a los ojos de los vecinos como "tirando para su gente".

En un caso y en otro, parte de los recursos sobre los que pasa a tener control "el político", tanto los públicos como su salario, deberá ser distribuida entre quienes le brindaron "apoyo". Pareciera que la lógica de igualdad que se espera gobierne en la comunidad trata de ser impuesta en el terreno de la política a partir de estas demandas. Quienes consideren que el compromiso -el 'pagaré'- no fue saldado, 'embargarán' no solo la reputación del político, sino por extensión la de su familia, una presión moral a la que todos “los políticos” se ven expuestos y por causa de la cual varios optaron por alejarse de la política. Las prácticas políticas también configuran las estrategias de reproducción social de los individuos y de las familias, y aquí no me refiero a lo económico, sino a la (re)producción de la reputación y honra del grupo social en cuestión, que determinara su posición en la sociedad.

Por (con)vivir junto a los electores, son "los políticos” locales - “los punteros" en la literatura sobre el clientelismo político- quienes están expuestos a la presión de la política de reputación, a la presión moral de su comunidad. Así, en determinados contextos, la pequeña política encuentra condiciones para imponerse y gobernar sobre la gran política.

\section{Reflexiones finales}

En el análisis empírico se torna dificultoso recortar algo semejante a una esfera social, la política en este caso, y diferenciarla de otras por medio de sus particularidades. La realidad es compleja siendo más frecuente la superposición e imbricación de lo que se considera propio de esas esferas, que su existencia en estado puro. Sin embargo, tiene sentido pensar la "política” como categoría analítica, pues es una categoría nativa significativa a partir de la cual los sujetos clasifican y significan prácticas, personas, espacios y tiempos y, en función de ello, definen sus modos de proceder, es decir, ordenan y experimentan su mundo social.

En Yavi observé una dualidad en torno a la significación y vivencia de la política. Cuando era enunciada en forma abstracta se le asignaba un sentido moralmente negativo, sin embargo cuando se la personalizaba en referentes locales los atributos podían ser positivos o persistir como negativos conforme el vínculo mantenido con las personas. Es que en esos casos, al igual que ocurre en las campañas electorales, los límites de lo político pueden ser fácilmente vulnerados ante referenciales de otras esferas sociales (familia, comunidad, religión, etc.). En la realidad empírica, especialmente en pequeñas sociedades, más que prácticas políticas puras (si es que existen), encontramos prácticas híbridas que se configuran a partir de las referencias y sentidos que las personas adjudican a los hechos, cosas y personas. La noción fenómeno social total, de Marcel Mauss (1974, p.15), nos alerta de que en cada acción social se expresan, al mismo tiempo y de manera intrincada, toda especie de instituciones (religiosas, morales, económicas, etc.) definiendo formas específicas de comportamiento y de configuración en cada sociedad. En el caso yaveño esta cualidad ganó expresividad a través de la objetivación analítica de las relaciones múltiples. Quien desdobla y disecciona la 
realidad social o los múltiples papeles sociales que despliegan los sujetos son los analistas para tornar aprehensible su objeto de estudio, pero la comprensión de éste no es factible sin reintegrar esa dimensión a la totalidad, pues así la experimentan los sujetos.

Un interrogante que surgió a lo largo del estudio es ¿por qué las personas se vinculan a un universo social a priori considerado inmoral? Ciertamente lo económico (acceso a programas sociales o empleo público) es un móvil en la vinculación con la institucionalidad política de los yaveños, que adquiere relevancia en un contexto de precarización de sus condiciones de vida. En las dos últimas décadas, la movilización de recursos de la institucionalidad de promoción social, se constituyó en una fuente estable y significativa en las economías de las familias campesinas. Comprender las condiciones de reproducción social de esos sujetos ya no es posible únicamente a partir de sus estrategias agropecuarias y de venta de mano de obra, es preciso integrarlas analíticamente a sus prácticas políticas. Este nuevo fenómeno ha sido escasamente tematizado en la academia argentina y constituye un campo de estudio para la comprensión de las condiciones de reproducción social de sujetos rurales subalternos.

La relación entre prácticas políticas y estrategias económicas de los sujetos subalternos ha sido observada en multiplicidad de estudios y configura un tema de debate académico. En algunas interpretaciones se tiende a reducir a la dimensión material los móviles del involucramiento político (Merklen, 2000). A esa lectura, se le contraponen interpretaciones que accionan móviles simbólicos, identitarios e ideológicos, que canalizados a través de estructuras políticas se orientarían a la transformación de la sociedad (Svampa y Pereyra, 2009, entre otros). Algunos autores/as observaron en ambos análisis cierta dicotomía que no coincide con la forma como los sujetos experimentan su involucramiento político. Si bien esos móviles suelen ser explicitados por las personas en la explicación de su participación política, es común que se imbriquen o incluso subordinen a otras vivencias menos conscientes y, por lo tanto, menos decibles aunque no menos intervinientes, como ser lealtades o compromisos afectivos, emociones, intereses recreativos y festivos o el placer por aprender (Auyero, 2001; Frederic, 2004; Quirós, 2011; Manzano, 2013; Berger, 2014, entre otros). Mis registros me llevan a converger con esta última interpretación y agrego que la política, por medio de la pequeña política, también interviene en la producción de reputaciones (u honores) personales y familiares y en la (re)producción de lazos sociales, constituyéndose en una dimensión de sus vidas que permea su cotidianeidad y nos permite comprender sus estrategias de reproducción social en sentido amplio, es decir, no sólo como sujetos económicos, sino sociales.

Durante el periodo en que visité la comarca, lejos de percibir la cotidianeidad local y la política como estáticas, fueron evidentes los cambios operados como parte de las tensiones internas de esa sociedad y de las interacciones que operan con procesos provinciales y nacionales. Reformas en el sistema político, crisis y reconversión de las estrategias de reproducción social de los yaveños, actualización de la cuestión indígena, irrupción de la institucionalidad de promoción social y de actores que impulsan nuevas visiones de mundo, prácticas y formatos organizativos favorecieron un mayor involucramiento de los yaveños en la vida política local, la revalorización de las comunidades en la arena política y el cuestionamiento de un modo de hacer política al que se le contrapone uno 'nuevo', que se nutre de los valores consagrados para la comunidad. Si bien se observan cambios, lejos se está del comportamiento corporativo que promueven los técnicos de MINK'A y muchos teóricos sociales, que pretenden que los sujetos subalternos se agrupen y movilicen en torno a intereses comunes o, aún mejor, identidades de clase con vistas a definir en términos ideológicos el modelo de sociedad deseado y a canalizarlo a través de estructuras políticas. Pero, como dijo Camilo, “cuando viene la política todos nos volvemos políticos” y los enfrentamientos y divisiones se infiltran entre quienes se perciben como iguales. ¿Cuáles son las condiciones de posibilidad para la permanencia de esas lógicas de comportamiento y la impermeabilidad a que otras lógicas (más ideológicas e impersonales) se impongan? 
A través de sus propuestas, los técnicos de MINK’A buscan “politizar” diversos aspectos del cotidiano de los campesinos. En su perspectiva, "politizar" supone promover un comportamiento corporativo ante los agentes en posiciones dominantes y (re)orientar cada acción hacia la concreción del "proyecto político". Pero la solidez de los vínculos en el Movimiento Campesino no siempre es suficiente como para anteponerse a la lealtad de redes de filiación fundadas en vínculos primarios (parentesco, vecindad, etc.).

Si bien los técnicos gozan de cierta autoridad y legitimidad para opinar acerca de cuestiones técnicoproductivas, e incluso sobre las estrategias de vinculación con agentes de otros universos sociales, "la política” local se les presenta como un terreno 'vedado'. Los lugareños no esperan ni desean que opinen sobre sus alineamientos. Ese 'desencuentro' surge de un 'malentendido' respecto de la propia idea y vivencia de la "política”. En cuanto los técnicos la piensan y asumen como algo abstracto, despersonalizado y dirigido a alterar las relaciones de poder locales, los yaveños la conciben a partir del estado de sus relaciones sociales. Opinar sobre los candidatos locales puede suponer cuestionar moralmente a parientes, amigos o vecinos. Lo que está en juego en ese proceder de los técnicos es introducir una visión de mundo y una lógica de acción que focaliza en la "toma de posición ideológica". No obstante, los posicionamientos de los pobladores locales ante los conflictos comunitarios y, en particular, en las contiendas electorales, como señala Alavi, lejos de estar determinados por cuestiones ideológicas, están asociados a la filiación y a las lógicas de acción inmanentes a las redes sociales -parentesco, religiosas, políticas, etc.- (1973, p.61). Motivados por promover un universo social menos excluyente, los técnicos no siempre se percatan de que la promoción de nuevas formas de sociabilización lleva implícita un cuestionamiento de cuño moral al modo de vida y principios de vinculación de los pobladores.

\section{Agradecimientos}

Para la elaboración del artículo se contó con apoyo financiero e institucional del Consejo Nacional de Investigaciones Científicas y Técnicas (PIP 112-20150100247-CO) y de la Agencia Nacional de Promoción Científica y Tecnológicas de Argentina (Proyecto PICT 2014-2676). Deseo agradecer a los pobladores de la comarca de Yavi por su disposición a compartir sus vivencias y cotidianeidad.

\section{Notas}

1 Las itálicas referencian palabras en otros idiomas o conceptos académicos, las comillas dobles (“...”) términos de terceras personas y las simples ( $` . .{ }^{\prime}$ ) expresiones propias que ilustran percepciones.

2 Dos compilaciones, ambas publicadas en 1977, Friends, Followers and Factions. A Reader in Political clientelism, organizada por Schmidt, Guasti, Landé y Scott, y Patrons and Clients in Mediterranean Societies, organizada por Ernest Gellner y John Waterbury, ofrecen una síntesis acabada de las bases sobre la que se configura la cuestión.

$\underline{3}$ Los nombres de las personas y de las organizaciones privadas son ficticios.

4 En Cowan Ros, 2013 se encuentra un análisis pormenorizado de la "comunidad” yaveña, en donde expongo el conjunto de registros empíricos sobre los que construyo el modelo aquí delineado.

$\underline{5}$ El Movimiento Campesino surge a fines de 1990 como una red de ONGs, entre las que se encontraba MINK’A, y posteriormente se reconfiguró en una organización territorial de base campesino-indígena. En 2005 llegó a agrupar 40 organizaciones sociales (de productores agropecuarios y artesanos) que nucleaban a 1200 familias de las regiones de Puna y de Quebrada de Humahuaca. Su filial yaveña agrupa alrededor de 
150 familias, la mitad de ellas pertenecientes a seis aldeas de la comarca. En la Red Kolla se articulan las comunidades indígenas del departamento de Yavi para luchar por sus derechos como pueblo.

6 Camilo es un hombre adulto, habita en la comunidad más populosa del distrito. Es empleado público en una escuela rural y productor agropecuario. Nótese cómo en su relato se verifica lo enunciado al principio de esta sección. A pesar de ser un importante dirigente comunitario, que durante años participó en el principal partido político de la oposición, inicia su relato desentendiéndose de "la política”, para luego explicitar su opinión y conocimiento sobre ésta. Tampoco se reconoció como "político", a pesar de haber sido candidato en las últimas elecciones.

$\underline{7}$ Narina es una mujer joven y madre soltera. Como productora agropecuaria desde hacía años participaba en el Movimiento Campesino, asumiendo funciones de coordinación de actividades. Meses antes de nuestro encuentro, se había vinculado a la facción gobernante, producto de su inclusión en el PJJHD, a través del cual se le adjudicaron labores en el edificio de la Comisión Municipal. A partir de desempeñar esa labor, en los años siguientes desempeñó cargos ejecutivos en la comisión Municipal lo que la convirtió en una de las referentes del oficialismo en Yavi.

8 Guillermina Espósito (2009) también observa transformaciones en la dinámica política de una localidad de la Quebrada de Humahuaca a partir del creciente protagonismo que adquiere un grupo de pobladores que comienza a operar como comunidad aborigen y a proponer "otra forma de hacer política”.

\section{Bibliografía}

Abduca, Ricardo (1993). Unidad campesina y semiproletarización: el caso de Yavi, Jujuy. Cuadernos de Antropología Social, 6, 5-43.

Abélès, Marc (1997). La antropología política: nuevos objetivos, nuevos objetos. Revista Internacional de Ciencias Sociales. 153, 319-332.

Alavi, Hamza (1973). Peasant Classes and Primordial Studies. The Journal of Peasant Studies, 1(1), 23-62.

Auyero, Javier (2001). La política de los pobres: las prácticas clientelísticas del peronismo. Buenos Aires: Manantial.

Bailey, Frederick (1971). Gifts and poison. En: Bailey (org), Gifts and poison (pp.1-25). Oxford: Basil Blackwell.

Balbi, Fernando y Rosato, Ana. (2003). Introducción. En Representaciones sociales y procesos políticos. Estudios desde la antropología social (pp. 1-30). Buenos Aires: Antropofagia.

Benedict, Burton (1980). Características sociológicas de los pequeños territorios y sus repercusiones en el desarrollo económico. En Banton, Michael (comp.), Antropología social de las sociedades complejas (pp. 40-52). Madrid: Alianza Editorial.

Berger, Matías (2014). Apenas bicicleta teníamos: El proceso de organización del Movimiento Campesino de Formosa en perspectiva histórica. Cuadernos de Antropología Social, 40, 125-147.

Boivin, Mauricio y Rosato, Ana (2003). Crisis, reciprocidad y dominación. En Constructores de Otredad. pp. 245-254. Buenos Aires: EUDEBA.

Bourdieu, Pierre (1994). Stratégies de reproduction et modes de domination. Actes de la recherche en sciences sociales. $105,3-12$. 
Cowan Ros, Carlos y Schneider, Sérgio (2008). Crisis y reconversión de estrategias de reproducción social campesinas en las tierras altas jujeñas, Argentina. Revista Internacional de Sociología, LXVI(50), 153-175.

Cowan Ros, Carlos (2013a). La trama de lo social: familia, vecindad y facciones en la producción de prácticas políticas en comunidades aborígenes de la Puna argentina. Madrid: EAE.

Cowan Ros, Carlos (2013b). Laberintos de emancipación. Reciprocidad y conflicto entre agentes de promoción social y dirigentes campesinos. Revista de Antropología Social, 22, 287-312.

Cowan Ros, Carlos (2014). Quando o beneficiário se personaliza-se: (re)significação de programas de promoção social em comunidades andinas. Revista Sociedade e Estado, 29(2), 607-633.

Espósito, Guillermina (2009). Candidato a candidato: una etnografía de las elecciones internas del PJ en una comunidad local del Noroeste Argentino. En: Boivin, Heredia y Rosato (comp.). Política, instituciones y gobierno (pp.51-78). Buenos Aires: Antropofagia.

Frederic, Sabina (2004). Buenos vecinos, malos políticos: moralidad y política en el Gran Buenos Aires. Buenos Aires: Prometeo.

Gluckman, Max (1975). The judicial process among the Barotse of Northern Rhodesia. En Vilhelm Aubert, Sociology of Law (pp. 161-170). UK: Penguin Education.

Heredia, Beatriz. (1996). Política, família, comunidade. En Goldam, Marcio e Palmeira, Moacir (org.), Antropologia, voto e representação política (pp. 57-71). Rio de Janeiro: ContraCapa.

Instituto Nacional de Estadísticas y Censos, (2012). Censo nacional de hogares, población y vivienda 2010: censo del Bicentenario : resultados definitivos, Serie $\mathrm{B} \mathrm{n}{ }^{\circ} 2.1^{\mathrm{a}}$ ed. Buenos Aires: INDEC.

Manzano, Virginia (2013). La política en movimiento: movilizaciones colectivas y políticas estatales en la vida del Gran Buenos Aires. Buenos Aires: Prohistoria.

Mauss, Marcel (1974). Ensaio sobre o dom. En Mauss, Sociologia e Antropologia. São Paulo: Editora Pedagógica e Universitária Ltda. e Editora da Universidade de São Paulo.

Merklen, Denis (2000). Vivir en los márgenes: la lógica del cazador. Notas sobre sociabilidad y cultura en los asentamientos del Gran Buenos Aires hacia fines de los 90'. En Svampa (ed.), Desde Abajo: la transformación de las identidades sociales. Buenos Aires: Biblos.

Palmeira, Moacir e Heredia, Beatriz (1997). Política ambígua. En Birman, Patrícia; Novaes, Regina e Crespo, Samira, O mal à brasileira (pp. 159-184). Rio de Janeiro: Editora UERJ.

Palmeira, Moacir (1992). Voto: racioanlidade ou significado? Revista Brasileira de Ciencias Sociais, 20, 26:30.

Pitt-Rivers, Julian (1971). Los hombres de la sierra: ensayo sociológico sobre un pueblo andaluz. BarcelonaMéxico: Ediciones Grijalbo.

Quirós, Julieta (2011). El porqué de los que van: peronistas y piqueteros en el Gran Buenos Aires (una antropología de la política vivida). Buenos Aires: Antropofagia.

Sahlins, Marshall (1981). Stone age economic. New York: Aline Publishing Co.

Svampa, Maristella y Pereyra, Sebastián (2009). Entre la ruta y el barrio: la experiencia de las organizaciones piqueteras. Buenos Aires: Biblos. 
Wolf, Eric (1980). Relaciones de parentesco, de amistad y de patronazgo en las sociedades complejas. En Banton (comp). Antropología social de las sociedades complejas (pp. 19-39). Madrid: Alianza Editorial. 